\title{
BMJ Open Development and validation of an instrument to assess treatment adherence for each individual drug taken by a patient
}

\author{
Stéphanie Sidorkiewicz, ${ }^{1,2}$ Viet-Thi Tran, ${ }^{2,3}$ Cécile Cousyn, ${ }^{3}$ Elodie Perrodeau, ${ }^{2}$ \\ Philippe Ravaud ${ }^{2,4,5}$
}

To cite: Sidorkiewicz S, Tran V-T, Cousyn C, et al. Development and validation of an instrument to assess treatment adherence for each individual drug taken by a patient. BMJ Open 2016;6: e010510. doi:10.1136/ bmjopen-2015-010510

- Prepublication history and additional material is available. To view please visit the journal (http://dx.doi.org/ 10.1136/bmjopen-2015010510).

Received 10 November 2015 Revised 3 February 2016 Accepted 5 February 2016

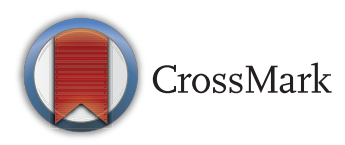

\footnotetext{
${ }^{1}$ Department of General Medicine, Paris Descartes University, Paris, France ${ }^{2}$ METHODS Team, Epidemiology and Statistics Sorbonne Paris Cité Research Centre, UMR 1153, INSERM, Paris, France

${ }^{3}$ Department of General Medicine, Paris Diderot University, Paris, France ${ }^{4}$ French Cochrane Centre, Paris, France

${ }^{5}$ Department of Epidemiology, Mailman School of Public Health, Columbia University, New York City, USA
}

Correspondence to Dr Viet-Thi TRAN; thi.tran-viet@htd.aphp.fr

\author{
ABSTRACT \\ Objective: To develop and validate an instrument to \\ assess adherence to each individual drug taken by \\ patients undergoing long-term treatment. \\ Design: Multicentre prospective observational \\ validation study.
}

Setting: Six general practitioners' clinics and 6 university hospitals in Paris, France.

Participants: Patients 18 years and older receiving at least one long-term treatment.

Methods: The instrument was developed from a literature search and interviews with experts. Clarity and wording were assessed during pilot testing with 51 patients. The tool was validated in a sample of consecutive patients. We assessed agreement between adherence measured with our tool and drug diaries and compared measurements from our instrument with (1) the Lu instrument; (2) the Adherence Estimator (AE); (3) patient's adherence assessed by physicians; (4) the Morisky Medication Adherence Scale-4 items (MMAS-4); and (5) the Treatment Burden Questionnaire (TBQ). Reliability was assessed by a test-retest method.

Results: A total of 243 patients taking 961 drugs were recruited in 2014. We found good agreement between adherence measured by our tool and drug diaries (intraclass correlation coefficient (ICC) $0.69,95 \% \mathrm{Cl}$ 0.34 to 0.91 ) and a linear relationship between measurement with our tool and (1) the Lu instrument $(p<0.01)$; (2) 2 items of the AE (perceived need for medication $(p<0.01)$ and concerns about medication $(p<0.01))$; (3) patients' adherence assessed by their physicians $(p<0.01)$; $(4)$ the MMAS-4 $(p<0.01)$ and $(5)$ the TBQ $(p<0.01)$. Reliability of the retest was good (ICC $0.67,95 \% \mathrm{Cl} 0.42$ to 0.85 ).

Conclusions: We developed an instrument with acceptable validity and reliability to assess adherence for each drug taken by patients, usable in hospital and primary care settings.

\section{INTRODUCTION}

The WHO suggested that 'solving the problem of medication non-adherence,

\section{Strengths and limitations of this study}

- Our instrument describes the different medication-taking behaviours for each drug taken by a patient. It may allow clinicians to identify how patients routinely manage their multiple drugs.

- Our instrument was validated in a sample of inpatients and outpatients.

- Measurements of adherence using our instrument illustrate the variability in adherence among the different drugs taken by a patient and the importance of rethinking adherence drug by drug.

- We did not compare measurements from our instrument against electronic monitoring devices.

- External validity of our instrument in other countries with different healthcare systems may be limited.

defined as the extent to which a person's behavior fails to coincide with medical advice, would be a greater improvement than any biomedical discovery'. ${ }^{1}$ Control of many illnesses depends on patient adherence to drug regimens. However, studies have shown that approximately $50 \%$ of patients stop taking their medications 6 months after drug initiation. $^{2} 3$ This situation may lead to increased hospitalisation rates and long-term mortality. ${ }^{45}$ Clinicians and researchers need tools to detect medication non-adherence. Many strategies have been developed: pill counting, prescription refill rates, drug diaries, biological markers, electronic monitoring devices, etc. ${ }^{1} 6{ }^{7}$ Each method captures different aspects of medication adherence. ${ }^{6}$ For example, electronic monitoring devices provide accurate information on time of container opening ${ }^{8}$ but may be intrusive and of limited use in routine practice for patients receiving multiple medications. In contrast, prescription refill rates can 
provide data on medication adherence in 'real life', but information on medication-taking behaviours (eg, schedule errors, omissions of doses, treatment discontinuation, etc) may be limited.

Measurement of adherence is a complex task because patients could adhere differently to their multiple drugs $^{9}{ }^{10}$ and exhibit various medication-taking behaviours. ${ }^{2} 11$ Thus, it is important to understand how patients routinely manage their treatment because different intake behaviours could be associated with different consequences. ${ }^{11}$ In routine care, self-reported questionnaires are the simplest and cheapest way to assess adherence, ${ }^{12} 13$ although patients tend to overestimate their adherence. ${ }^{3}{ }^{14}$ There are many questionnaires in the literature to assess adherence, but most have been developed for specific conditions or treatments, ${ }^{15-17}$ and their measurement often focuses on predictors or factors of adherence ${ }^{18}$ or on quantitative rates of medication intake. ${ }^{19}$

In this study, we aimed to develop and validate a selfreported questionnaire to assess medication adherence for each individual drug taken by patients with longterm drug treatment, suitable across any treatment context.

\section{METHODS}

This project involved: (1) theoretical conceptualisation of the tool, (2) development of the tool and (3) assessment of its measurement properties.

\section{Theoretical conceptualisation of the tool}

The theoretical conceptualisation of the tool was based on the taxonomy published by Vrijens et $a l,{ }^{20}$ which describes adherence as a process divided into three quantifiable phases: initiation (first dose taken), implementation (defined as the extent to which a patient's actual dosing corresponds to the prescribed dosing regimen) and discontinuation (the end of the therapy). Persistence is defined as the length of time between initiation and the last dose taken. According to this conceptual framework, we aimed to develop a tool describing several medication-taking behaviours (ie, discontinuation, drug holidays, missing doses and schedule errors) to capture implementation and persistence. Indeed, it could help clinicians better understand how patients manage their treatments and find appropriate patient-centred solutions.

To elaborate the items of the tool, we used the results from three systematic reviews ${ }^{6}{ }^{12}{ }^{21}$ completed by a search in MEDLINE via PubMed for recent studies describing medication adherence and questionnaires to assess it. Published self-reported questionnaires are often specific to disease areas or treatments, ${ }^{15-17} 22{ }^{23}$ focused on patient beliefs, ${ }^{18}{ }^{24}$ or not adapted to assess differential adherence for each drug taken by the patient. ${ }^{25}$ In addition, most of them provide a single value for measurement of adherence (eg, considering a patient who takes $<80 \%$ of the doses as 'non-adherent'). ${ }^{3}$ This approach remains satisfactory for comparing patients' adherence in trials focused on one drug. However, it may be limited in routine practice as it does not inform on differences in adherence to multiple drugs. ${ }^{9}{ }^{10}$ To the best of our knowledge, only a few published questionnaires $^{26} 27$ take into account the fact that patients may adhere differently to multiple medications. We aimed to provide complementary information to these tools by describing medication-taking behaviours. We also wanted to design a tool suitable for any treatment context, and able to assess adherence for each medication taken by patients.

\section{Development of the tool}

We followed a recommended multistep approach to develop the tool. ${ }^{28}$

\section{Elaboration of the tool}

After a review of the literature, a working group composed of a medical resident (CC), two general practitioners (SS and V-TT) and a professor of epidemiology (PR) drafted five questions related to (1) early discontinuation of the drug; (2) systematic omission of a daily dose (eg, at noon); (3) drug holidays; (4) skipping doses and (5) schedule errors. For each question, we devised possible answers with practical examples and pictographs. Our approach was pragmatic: we asked patients to select the answer that best applied to them, even if their drug intakes did not exactly fit the suggested answers. We hypothesised that this approach would be easier for patients than asking them for an accurate number of doses missed. ${ }^{14}$ For example, we considered that a patient usually missing a single dose every month would have had difficulties choosing between 'once a month' and 'less than once a month'.

\section{Interviews of experts}

One investigator (SS) interviewed four experts-two physicians, one pharmacist and one methodologist-with research experience in the field of medication adherence. During semistructured interviews, she asked them about (1) the relevance of the tool; (2) the clarity of questions, possible answers, pictographs and (3) the global feasibility of the questionnaire. The working group considered their comments and modified the preliminary tool. This step ensured the tool's content validity.

\section{Pilot testing}

We performed a two-step pilot testing in April 2014 Consecutive patients were recruited in one university hospital and four general practices in Paris, France. First, we asked 34 consecutive patients to complete the questionnaire. Then investigators performed a double interview method: they asked participants to explain what each item meant to them and why they chose a particular response. Discrepancies between what was intended and what was understood were noted. ${ }^{29}$ 
Our working group adapted the tool according to patients' answers. In a second step, we tested the revised instrument with 17 different patients whose responses suggested good acceptability of the tool. The resulting tool (online supplementary figure S1) contained five questions with two or three possible answers to each question. Each question was illustrated with practical examples and pictographs to help patients recognise their behaviours. ${ }^{30} 31$ We used non-threatening sentences adapted from the literature ${ }^{3}$ to reduce social desirability bias. ${ }^{6}$

Characteristics of the 51 patients in the pilot test are detailed in online supplementary table S1.

\section{Definition of adherence at drug level}

On the basis of our clinical experience and the literature, ${ }^{3}{ }^{32}$ we defined six drug adherence levels for a given drug (table 1). Level 1 corresponded to high drug adherence (no drug holidays, no missing doses and no schedule errors) and level 6 corresponded to drug discontinuation.

\section{Definition of adherence at the patient level}

To allow comparisons between our tool and other measures of adherence, we defined patient adherence level as the adherence level for the drug for which the patient was the most non-adherent (see online supplementary table S2). We performed a sensitivity analysis to explore whether other definitions (patient adherence level defined as the mean or median drug adherence level) would change our results.

\section{Evaluation of the tool's measurement properties}

We evaluated the instrument's properties by studying validity and reliability. We validated the instrument at the drug and patient levels.

\section{Participants and drugs}

We recruited consecutive patients in six general practices and six care units of university hospitals in the

Table 1 Six levels of drug adherence

\begin{tabular}{ll}
$\begin{array}{l}\text { Drug adherence } \\
\text { level }\end{array}$ & $\begin{array}{l}\text { Answers selected by the patient } \\
\text { (best applied to drug intake) }\end{array}$ \\
\hline $\begin{array}{l}\text { 1. High drug } \\
\text { adherence }\end{array}$ & $\begin{array}{l}\text { No drug holidays, no missing } \\
\text { doses and no schedule errors } \\
\text { No drug holidays and no missing } \\
\text { 2. Good drug } \\
\text { adherence }\end{array}$ \\
$\begin{array}{l}\text { doses; schedule errors } \geq 4 \mathrm{~h} \\
\text { Moderate drug } \\
\text { adherence }\end{array}$ & $\begin{array}{l}\text { No drug holidays; missing doses } \\
\text { once or twice a month and/or }\end{array}$ \\
schedule errors $\geq 12 \mathrm{~h}$
\end{tabular}

Ile-de-France region, France. Patients were eligible if they were $\geq 18$ years old; were receiving at least one drug requiring long-term use initiated for at least 30 days; gave written consent to participate; and were able to write answers in French. We excluded patients with cognitive impairment or a language barrier and those who received medication from a nurse or a home care provider. We did not include drugs prescribed if needed or for an acute condition.

The list of drugs taken by the patient was obtained by a review of medical records by the investigators (SS or CC) and by asking the patient if he or she was using additional over-the-counter medications. Drugs were categorised independently into drug classes by two investigators (CC and SS) using a classification adapted from pharmacy claims. ${ }^{33}$

\section{Assessment of the tool's measurement properties at the drug level \\ Validity}

Criterion validity was assessed by evaluating the agreement between the level of adherence to the drug assessed with our tool and drug diaries. Each patient was asked to complete a 14-day diary for only one drug chosen randomly among his or her medications to improve acceptability and feasibility. One investigator (SS) assessed the drug adherence level in drug diaries. Each reported drug intake was considered a taken dose and each missing intake a missing dose; schedule errors were assessed by counting time intervals between reported doses.

Construct validity was assessed by comparing measurements from our instrument and the following measures. Among possible scales, we chose those usable across any treatment context and requiring a short response time in order to minimise the burden for respondents:

$\mathrm{Lu}$ et $a l \mathrm{~s}^{14}$ instrument was completed by patients for all medications. This self-reported adherence instrument has been validated in HIV-positive patients and measures patients' average ability to take their medication as prescribed. The instrument uses a six-step scale ranging from 'very poor' to 'excellent'. We generated a French-language version of this instrument usable for each prescribed drug during a translation procedure ${ }^{34} 35$ detailed in online supplementary table S3. Cognitive testing performed during the first pilot testing led to adaptation of the instrument in an 11-step rating scale ranging from 0 (very poor) to 10 (excellent). We hypothesised a linear relationship between measurement by our tool and the Lu instrument.

The Adherence Estimator $(\mathrm{AE})^{18}$ was completed by patients for all medications. This self-reported adherence instrument is a validated three-item tool that predicts intentional non-adherence associated with beliefs about medicines. Scores for each item (perceived need for medication, perceived concerns about medication and perceived medication affordability) range from 1 (agree completely) to 6 (disagree completely). We 
generated a French-language version of this instrument (see online supplementary table S3). We hypothesised a linear relationship between measurement by our tool and the AE instrument.

Drug adherence for each medication was assessed by the physicians taking care of the patients. They were asked to best estimate the patient's adherence for each drug using an 11-step rating scale ranging from 0 (very poor) to 10 (excellent). We hypothesised a linear relationship between measurement by our tool and physicians' evaluation.

\section{Reliability}

Reliability of the measurement of adherence at drug level was determined by a test-retest method. Patients completed our instrument at baseline and after 1-month. ${ }^{36}$ Retest questionnaires were sent by postal mail to patients.

\section{Assessment of the tool's measurement properties at the patient level \\ Validity}

Construct validity was assessed by comparing measurements from our instrument and the following measures: the Morisky Medication Adherence Scale-4 items $\left(\right.$ MMAS-4) ${ }^{25}$ and the Treatment Burden Questionnaire (TBQ). ${ }^{37}$

The MMAS- $4^{25}$ was initially developed among patients diagnosed with hypertension. It has been validated in inpatients and outpatients, various conditions and treatments. It contains four questions with yes $(0)$ or no (1) answers. The item scores are summed to define three levels of adherence: 0 (high adherence), 1-2 (medium adherence), and 3-4 (low adherence). The questionnaire was designed to obtain a global score per patient. We hypothesised a positive correlation between overall patient adherence by our tool (online supplementary table S2) and the MMAS-4 score.

The $\mathrm{TBQ}^{37}$ aims to assess the workload of healthcare for patients and its impact on quality of life. This scale contains 13 items with an 11-step rating scale ranging from 0 (not a problem) to 10 (big problem) and was designed to obtain a global score per patient. We hypothesised a positive correlation between overall patient adherence by our tool and the TBQ score. ${ }^{37} 38$

\section{Reliability}

Reliability of the measurement of adherence at patient level was determined by a test-retest method. Patients completed our instrument at baseline and after 1-month. ${ }^{36}$ Retest questionnaires were sent by postal mail to patients.

\section{Statistical analysis}

Data are described with numbers (percentages) for categorical variables and means (SD) or medians (IQR) for quantitative variables. Agreement between measurement from our tool and drug diaries was assessed by the intraclass correlation coefficient (ICC) ${ }^{28}$ and considered acceptable at ICC $>0.60 .^{28} 39$ The $95 \%$ CIs were determined by a bootstrap method. Similarly, the test-retest agreement was assessed using ICC.

To assess construct validity, we used mixed linear models with the identity of the patient taking the drug as a random effect to account for the clustered structure of our data (different drugs taken by the same patient). We considered five models to compare drug adherence level measured with our tool and the Lu questionnaire, the three items from the $\mathrm{AE}$ and physicians' evaluations.

Correlations between patient level of adherence obtained with our tool and the MMAS-4 global score or TBQ score were assessed by Spearman correlation coefficient $\left(r_{s}\right)$ and considered high at $r_{s}>0.5$ and moderate at $r_{\mathrm{s}}=0.35-0.50 .{ }^{40}$ All statistical tests were two-sided with $\mathrm{p}<0.05$ being considered statistically significant.

To better understand the relationship between drug adherence assessed by our tool and the global score obtained by the MMAS-4, we used a graphical representation. We classified all patients by MMAS-4 score level (low, medium and high) and represented, for each patient, all prescribed drugs coloured according to the six drug adherence levels of our tool.

We used complete case analysis to manage missing data. All statistical analyses involved use of R V.2.13.1 (http://www.r-project.org).

\section{RESULTS}

\section{Participants and drugs}

From May to August 2014, 243 patients were recruited (median age 59.1 years (IQR 42.5-70.6 years)); 163 $(67.1 \%)$ were women and $155(63.8 \%)$ were outpatients (table 2). Patients took a total of 961 medications (median 3 (IQR 2-5) per patient), corresponding to 292 distinct drugs. Among the 243 patients who responded to the study questionnaire, all completed our instrument for at least one medication, which allowed us to define drug adherence levels for 913/961 (95.0\%) medications. A total of $210(86.4 \%)$ patients completed the instrument for all their medications. Most of the prescribed drugs were cardiac agents, representing 222 $(23.1 \%)$ drugs. Figure 1 shows the results by different drug classes (see classification detailed in online supplementary table S4).

\section{Assessment of the measurement properties of the developed tool at the drug level Validity}

A total of 37 patients $(39.7 \%$ of patients who agreed to complete diaries) returned their 14-day drug diaries. Agreement between adherence measured by our tool and drug diaries was good, with ICC 0.69 (95\% CI 0.34 to 0.91 ) (see online supplementary table S5).

We found a linear relationship between adherence measured by our tool and with the $\mathrm{Lu}$ questionnaire $(p<0.01)$. Mean ratings increased from 2.1 (SD 3.8) for 
Table 2 Demographic and clinical characteristics of patients $(n=243)$

\begin{tabular}{|c|c|c|}
\hline Characteristics & Value & $\begin{array}{l}\text { Missing } \\
\text { data }\end{array}$ \\
\hline Age-median (IQR) & $59.1(42.5-70.6)$ & 2 \\
\hline \multicolumn{3}{|l|}{ Sex-number (\%) } \\
\hline Male & $80(32.9)$ & 0 \\
\hline Marital status-number (\%) & & 0 \\
\hline Married or civil union & $102(42.0)$ & \\
\hline Live-in partner & $17(7.0)$ & \\
\hline Single & $60(24.7)$ & \\
\hline Separated & $39(16.0)$ & \\
\hline Widowed & $25(10.3)$ & \\
\hline Education level一number (\%) & & 5 \\
\hline Primary school & $48(20.2)$ & \\
\hline Secondary school & $101(42.4)$ & \\
\hline College & 89 (37.4) & \\
\hline $\begin{array}{l}\text { Place of recruitment-number } \\
(\%)\end{array}$ & & 0 \\
\hline Inpatients & $88(36.2)$ & \\
\hline Outpatients & $155(63.8)$ & \\
\hline \multicolumn{3}{|c|}{ Strategies used by patients-number $(\%)^{*}$} \\
\hline $\begin{array}{l}\text { Places or times of everyday } \\
\text { life }\end{array}$ & $142(58.2)$ & \\
\hline Alarms, reminders, diaries & $27(11.1)$ & \\
\hline Kept medication in bag & 52 (21.3) & \\
\hline Ritual gesture & $36(14.8)$ & \\
\hline Tablet organiser & $45(18.4)$ & \\
\hline Help of a relative & $17(7.0)$ & \\
\hline Nothing & $35(14.3)$ & \\
\hline $\begin{array}{l}\text { Number of medications per } \\
\text { patient-median (IQR) }\end{array}$ & $3.0(2.0-5.0)$ & \\
\hline \multicolumn{3}{|c|}{ Self-reported chronic conditions-number $(\%)^{*}$} \\
\hline High blood pressure & $52(21.4)$ & \\
\hline Diabetes & $37(15.2)$ & \\
\hline Oral contraception & $36(14.8)$ & \\
\hline Heart diseases & $31(12.8)$ & \\
\hline Pulmonary diseases & $31(12.8)$ & \\
\hline Rheumatological diseases & $27(11.1)$ & \\
\hline Psychiatric diseases & $26(10.7)$ & \\
\hline $\begin{array}{l}\text { Cancer and haematological } \\
\text { malignancy }\end{array}$ & $13(5.3)$ & \\
\hline Other diseasest & $71(29.2)$ & \\
\hline
\end{tabular}

*Patients could have reported many strategies and many chronic conditions.

†Other diseases include neurological diseases, HIV infection, gastro-oesophageal reflux disease, inflammatory bowel diseases, systemic diseases, migraines, allergies, urological disorders and hormonal replacement therapy.

discontinued drugs (adherence level 6) to 9.9 (SD 0.8) for drugs for which patients were highly adherent (adherence level 1) (table 3).

Drug adherence measured by our tool and measures obtained by the $\mathrm{AE}$ were linearly related. The mean $\mathrm{AE}$ score about perceived need for medication decreased from 2.5 (SD 2.0) for discontinued drugs to 1.3 (SD 0.8) for drugs for which patients were perfectly adherent $(p<0.01)$ and the mean $\mathrm{AE}$ about the score for perceived concerns about medication increased from 4.5
(SD 1.7) for discontinued drugs to 5.1 (SD 1.5) for drugs for which patients were highly adherent $(p<0.01)$. However, we found no significant association with perceived affordability of drugs $(\mathrm{p}=0.28)$.

A total of 57 physicians (45\% of sent questionnaires) evaluated 501 drugs taken by their patients. Drug adherence measured by our tool and physicians' perception of patient adherence was linearly related $(\mathrm{p}<0.001)$. However, physicians rated adherence highly for discontinued drugs (mean score 6.3 (SD 3.2)).

\section{Reliability}

Test-retest results were obtained for 53 patients taking a total of 203 drugs. Agreement was good for drug adherence level, with ICC 0.67 (95\% CI 0.42 to 0.85 ) (see online supplementary table $\mathrm{S} 6$ ).

\section{Assessment of the measurement properties of the developed tool at the patient level \\ Validity}

We found a weak correlation between patient adherence levels obtained with our tool and the MMAS-4 score $\left(\mathrm{r}_{\mathrm{s}}=0.28, \mathrm{p}<0.01\right)$. We found variability in adherence among the different drugs taken by patients (figure 2): patients could perfectly adhere to one drug and could have discontinued another one. We found a weak correlation between global patient adherence obtained by our tool and TBQ scores $\left(\mathrm{r}_{\mathrm{s}}=0.32, \mathrm{p}<0.01\right)$.

Sensitivity analysis exploring different definitions of patient adherence level did not change results as detailed in online supplementary table S7.

\section{Reliability}

Test-retest results were obtained for 53 patients taking a total of 203 drugs. Agreement was good for patient adherence levels, with ICC 0.80 (95\% CI 0.65 to 0.91$)$.

\section{DISCUSSION}

In this study, we developed a new tool providing an accurate assessment of adherence by describing several medicine-taking behaviours (ie, discontinuation, drug holidays, missing doses and schedule errors) for each drug taken by a patient. To the best of our knowledge, this tool is the first to assess adherence for each drug taken by patients and taking into account medicinetaking behaviours. Its response rate suggests good acceptability.

All hypotheses for construct validity were verified, except for the expected relationship between measurement of adherence using our tool and the $\mathrm{AE}$ question about affordability of the drug. This result may be explained by the poor suitability of this question for French patients: in France, the national public health insurance programme guarantees healthcare free of charge for patients with chronic conditions.

Measurements of adherence at patient level using our tool were weakly correlated with measures of the 


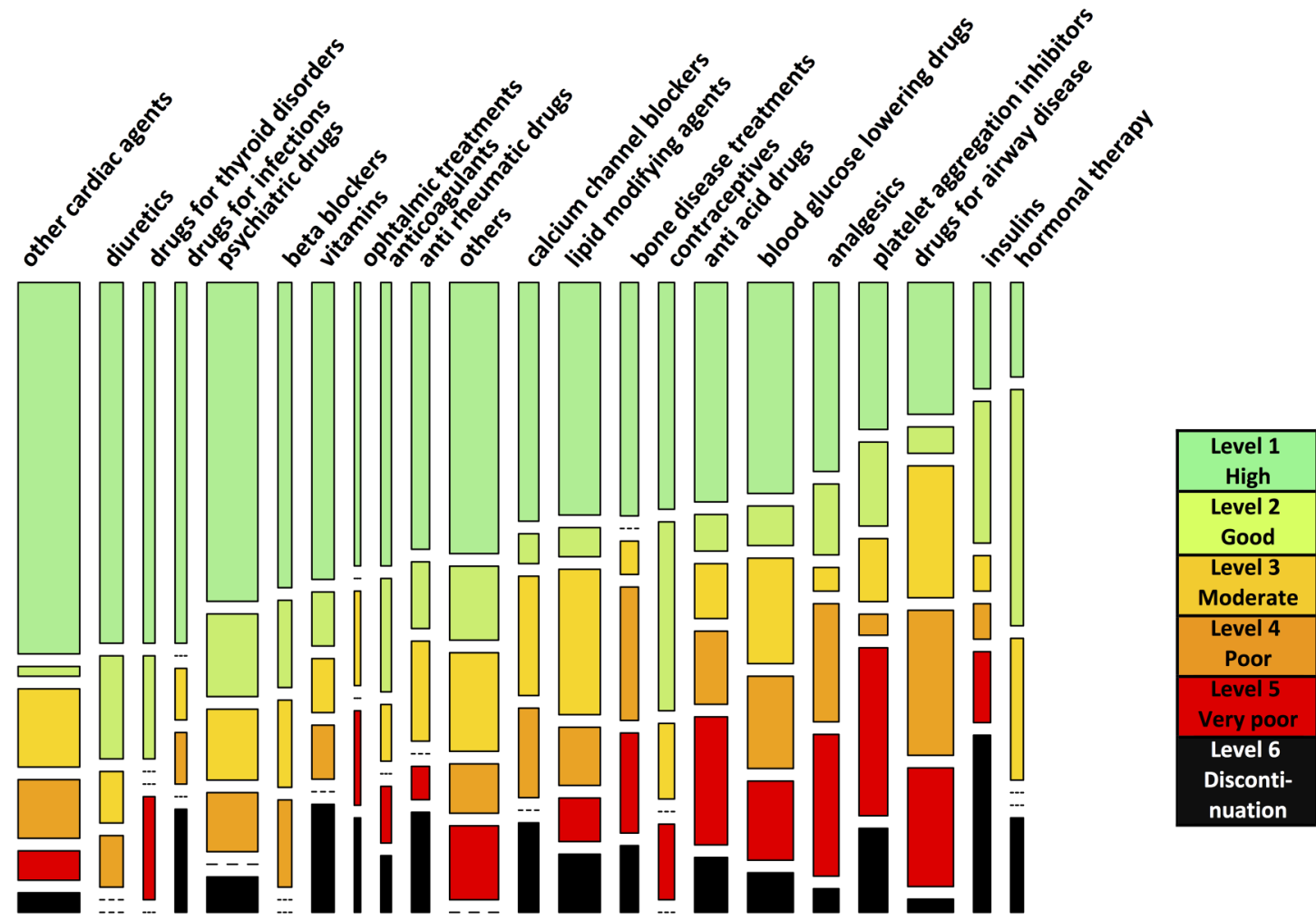

Figure 1 Drug adherence by different medication classes. Each bar corresponds to a medication class. The width of a bar is proportional to the number of drugs of the class in the study. Colours correspond to drug adherence levels.

MMAS-4. These findings could be related to poor psychometric properties of our tool or variability in adherence among the different drugs taken by patients, as illustrated in figure 2. This is an example of the difficulties encountered when defining adherence at the patient level (eg, considering a patient as 'adherent' or 'non-adherent' without exploring the differences among different drugs). Measurements of adherence at the patient level using our tool were weakly correlated with measures of the TBQ. This result was expected in part because the TBQ measures burden of treatment globally, including components other than problems with medications.

In the present study, we developed a self-reported instrument to assess adherence. We acknowledge that patient-reported outcomes are more at risk of respondent bias than are other measures of adherence, such as electronic devices. However, they represent the easiest way to assess adherence in routine practice. These different methods are complementary and all have advantages and limits. Use of a given method should be guided by the specific purposes of adherence studies. ${ }^{6}$ In this study, we did not compare measurements of adherence using our tool with electronic monitoring devices, prescription refill rates or pill counts. Moreover, we did not assess the responsiveness of our instrument which could be explored in future studies. ${ }^{41}$

The main strength of this study is the large diversified recruitment (inpatients and outpatients with different conditions and various treatment regimens), thus ensuring the suitability of our tool for assessing adherence across any disease or treatment context.

Moreover, our estimates of adherence assessed by our tool at the drug level may be more accurate than those obtained with other tools: indeed, we did not 'judge' whether a patient was adherent or not, but we assessed specific behaviours for specific medications with a 'no-blame' approach, suggesting to the patient that nonadherence may be the norm or usual. This finding was illustrated by the lower ceiling effect with our tool than with other measures of adherence (Lu's questionnaire, AE, MMAS-4). As a result, asking about different medicinetaking behaviours for each individual prescribed drugs could avoid a rating value judgement and reduce overestimation of self-reported adherence. However, these findings need to be confirmed in other studies.

This study has limitations. First, our tool is not suitable for drugs taken several times a day or irregularly (eg, once a month). Moreover, it does not provide information about occasional change in dosage by the patient or accurate frequency of behaviours. This was a conceptual choice: we preferred to develop a simple and easy-to-use tool usable for studies or daily practice, in which patients could select the answer that best applied to them while minimising the respondent's burden. Second, we collected only names of the prescribed drugs. As a result, our tool does not provide information about pill colour, galenic form or generic drug use, 
Table 3 Comparison between drug adherence levels obtained by our tool and other measures at the drug level ( $n=913$ drugs)

\begin{tabular}{|c|c|c|c|c|c|c|c|}
\hline \multicolumn{7}{|c|}{ Drug adherence levels obtained by our tool } & \multirow[b]{2}{*}{ p Value ${ }^{x}$} \\
\hline & $\begin{array}{l}\text { Level 1: } \\
\text { high adherence } \\
(\mathrm{n}=431)\end{array}$ & $\begin{array}{l}\text { Level 2: } \\
\text { good adherence } \\
(n=104)\end{array}$ & $\begin{array}{l}\text { Level 3: } \\
\text { moderate adherence } \\
(n=153)\end{array}$ & $\begin{array}{l}\text { Level 4: } \\
\text { poor adherence } \\
(n=102)\end{array}$ & $\begin{array}{l}\text { Level 5: } \\
\text { very poor adherence } \\
(n=79)\end{array}$ & $\begin{array}{l}\text { Level 6: } \\
\text { discontinuation } \\
(n=44)\end{array}$ & \\
\hline $\begin{array}{l}\text { Patient-reported ability to } \\
\text { take the medication as } \\
\text { prescribed (Lu et al) } \dagger \\
\text { Adherence Estimator }\end{array}$ & $9.9(0.8)$ & $9.7(0.6)$ & $8.7(1.6)$ & $7.9(2.1)$ & $6.6(3.4)$ & $2.1(3.8)$ & $<0.01$ \\
\hline $\begin{array}{l}\text { Patient's evaluation of the } \\
\text { medication's importance }\end{array}$ & $1.3(0.8)$ & $1.4(0.8)$ & $1.5(0.8)$ & $1.4(0.9)$ & $2.5(1.7)$ & $2.5(2.0)$ & $<0.01$ \\
\hline $\begin{array}{l}\text { Patient's evaluation of the } \\
\text { medication's risk/benefit } \\
\text { balancef }\end{array}$ & $5.1(1.5)$ & $4.8(1.8)$ & $4.8(1.5)$ & $5.0(1.4)$ & $4.5(1.8)$ & $4.5(1.7)$ & $<0.01$ \\
\hline $\begin{array}{l}\text { Patient's evaluation of the } \\
\text { medication's financial } \\
\text { burden } \neq\end{array}$ & $5.6(1.2)$ & $5.4(1.5)$ & $5.1(1.8)$ & $4.8(1.8)$ & $4.9(1.8)$ & $4.7(2.0)$ & 0.28 \\
\hline $\begin{array}{l}\text { Physician's perception of } \\
\text { patient's ability to take } \\
\text { medication as prescribed§}\end{array}$ & $8.6(1.9)$ & $8.1(2.1)$ & $8.8(1.8)$ & $7.6(2.2)$ & $7.3(2.6)$ & $6.3(3.2)$ & $<0.01$ \\
\hline
\end{tabular}




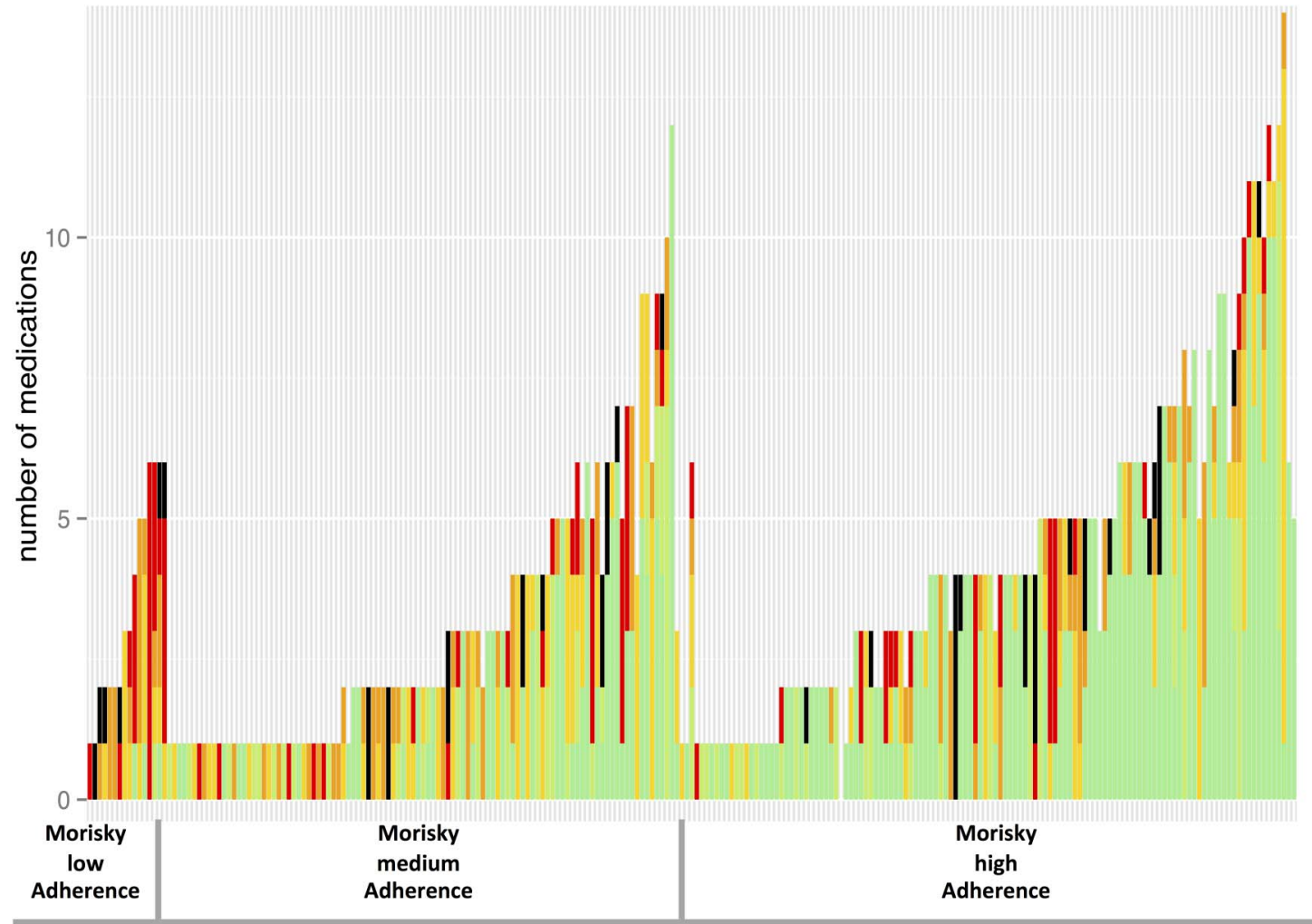

Figure 2 Drug adherence for each drug taken by the patient according to the Morisky Medication Adherence Scale-4 items (MMAS-4) level. Each bar corresponds to a patient: patients were ordered by the MMAS-4 score and number of prescribed drugs. The height of a bar is proportional to the number of drugs taken by the patient. Colours correspond to drug adherence levels: green, high adherence; light green, good adherence; deep yellow, moderate adherence; orange, poor adherence; red, very poor adherence; black, discontinuation.

which could have an impact on drug non-adherence. ${ }^{42} 43$ Third, our sample was a convenience sample and was not representative of the population of patients taking long-term treatments, especially in other countries with different healthcare systems. Fourth, only a small sample of patients completed and returned drug diaries, generating wide CIs. This finding suggests poor acceptability of assessment of adherence with drug diaries, which may be too intrusive for routine use. In addition, diaries may be considered as interventions, but this would not have impacted estimates of patient adherence using our tool, as our tool was filled before the diaries were completed. Finally, global patient adherence level was arbitrarily defined. However, we assessed whether different definitions of patient level of adherence affected our results and did not find any change in our findings (online supplementary table S7). It is important to note that our definition of adherence at patient level was mainly for allowing comparisons between our tool and other measurements at patient level. For practice, we recommend using our tool to assess adherence at drug level.

This study may have several clinical implications. First, physicians rated adherence highly for discontinued drugs, which highlights that they were often unaware of how patients managed their different medications. They should be aware of the importance of assessing drug adherence during consultations or prescription refill requests. Second, we found variability in adherence to the different drugs taken by a given patient. Adherence may depend on multiple factors, including the nature/indication of the drug, as suggested by figure 1 . These findings support the literature, which has shown that patient adherence is affected by different beliefs and experiences about their medications, conditions and the healthcare system. ${ }^{344}$ Physicians caring for patients under long-term treatment should take into account these factors to understand the complexity of medication intake. Asking about different medicine-taking behaviours rather than simply categorising patients as 'adherent' or 'non-adherent' could avoid value judgements and facilitate patient-physician discussions about medications. More work is needed to implement our instrument in the clinic and to assess its impact on treatment decisions in routine practice.

\section{CONCLUSION}

We developed a new instrument with acceptable validity and reliability to assess drug adherence, providing information about medicine-taking behaviours for patients with long-term therapies and with a new 'drug-by-drug' perspective. Our self-reported adherence tool could complement other measurements of treatment adherence in routine practice. We found variability in the different drugs taken by a patient and poor awareness of 
patient non-adherence by physicians. These findings should encourage physicians to ask about medicationtaking during consultations and to assess adherence not globally per patient but rather for each individual drug.

Acknowledgements The authors thank Caroline Barnes and Cathia Zak for help with questionnaire translation and Laura Smales for reviewing the manuscript before submission. They are particularly indebted to Gerard Reach, Jean-François Bergmann, Virginie Savoldelli and Fabienne Marcellin for sharing their time and expertise during meetings.

Contributors SS was involved in the study conception, writing of the manuscript, meeting experts, elaborating the tool, recruiting patients, interpreting results and drafting the manuscript. V-TT and PR were involved in the study conception, elaborating the tool, interpreting results and drafting of the manuscript. CC was involved in elaborating the tool and recruiting patients. EP was involved in statistical analysis. PR is the guarantor.

Funding The study was supported by an academic grant from the programme 'Equipe espoir de la Recherche', Fondation pour la Recherche Médicale, Paris, France (number DEQ20101221475)

Disclaimer The funders had no role in study design, data collection and analysis, decision to publish, or preparation of the manuscript.

Competing interests None declared.

Patient consent Obtained.

Ethics approval The study protocol was approved by the Institutional Review Board of University Paris Descartes (IRB 0001072).

Provenance and peer review Not commissioned; externally peer reviewed.

Data sharing statement No additional data are available.

Open Access This is an Open Access article distributed in accordance with the Creative Commons Attribution Non Commercial (CC BY-NC 4.0) license, which permits others to distribute, remix, adapt, build upon this work noncommercially, and license their derivative works on different terms, provided the original work is properly cited and the use is non-commercial. See: http:// creativecommons.org/licenses/by-nc/4.0/

\section{REFERENCES}

1. Sabate E. Adherence to long-term therapies: evidence for action. Geneva, Switzerland: World Health Organization, 2003.

2. Vrijens B, Vincze G, Kristanto P, et al. Adherence to prescribed antihypertensive drug treatments: longitudinal study of electronically compiled dosing histories. BMJ 2008;336:1114-17.

3. Osterberg L, Blaschke T. Adherence to medication. N Engl J Med 2005:353:487-97.

4. Simpson SH, Eurich DT, Majumdar SR, et al. A meta-analysis of the association between adherence to drug therapy and mortality. BMJ 2006:333:15.

5. Ho PM, Rumsfeld JS, Masoudi FA, et al. Effect of medication nonadherence on hospitalization and mortality among patients with diabetes mellitus. Arch Intern Med 2006:166:1836-41.

6. Lehmann A, Aslani P, Ahmed R, et al. Assessing medication adherence: options to consider. Int J Clin Pharm 2014;36:55-69.

7. Marcellin F, Spire B, Carrieri MP, et al. Assessing adherence to antiretroviral therapy in randomized HIV clinical trials: a review of currently used methods. Expert Rev Anti Infect Ther2013;11: 239-50.

8. Urquhart J. The electronic medication event monitor. Lessons for pharmacotherapy. Clin Pharmacokinet 1997;32:345-56.

9. Gardner EM, Sharma S, Peng G, et al. Differential adherence to combination antiretroviral therapy is associated with virological failure with resistance. AIDS 2008;22:75-82.

10. Viana M, Laszczynska O, Mendes S, et al. Medication adherence to specific drug classes in chronic heart failure. J Manag Care Spec Pharm 2014;20:1018-26.

11. Osterberg LG, Urquhart J, Blaschke TF. Understanding forgiveness: minding and mining the gaps between pharmacokinetics and therapeutics. Clin Pharmacol Ther 2010;88:457-9.

12. Garfield S, Clifford S, Eliasson L, et al. Suitability of measures of self-reported medication adherence for routine clinical use: a systematic review. BMC Med Res Methodol 2011;11:149.
13. National Collaborating Centre for Primary Care. Medicines adherence: involving patients in decisions about prescribed medicines and supporting adherence. London: NICE, 2009

14. Lu M, Safren SA, Skolnik PR, et al. Optimal recall period and response task for self-reported HIV medication adherence. AIDS Behav 2008;12:86-94.

15. Chesney MA, Ickovics JR, Chambers DB, et al. Self-reported adherence to antiretroviral medications among participants in HIV clinical trials: the AACTG adherence instruments. Patient Care Committee \& Adherence Working Group of the Outcomes Committee of the Adult AIDS Clinical Trials Group (AACTG). AIDS Care 2000;12:255-66.

16. Thompson K, Kulkarni J, Sergejew AA. Reliability and validity of a new Medication Adherence Rating Scale (MARS) for the psychoses. Schizophr Res 2000;42:241-7.

17. Mannheimer SB, Mukherjee R, Hirschhorn LR, et al. The CASE adherence index: a novel method for measuring adherence to antiretroviral therapy. AIDS Care 2006;18:853-61.

18. McHorney CA. The Adherence Estimator: a brief, proximal screener for patient propensity to adhere to prescription medications for chronic disease. Curr Med Res Opin 2009;25:215-38.

19. Gehi AK, Ali S, Na B, et al. Self-reported medication adherence and cardiovascular events in patients with stable coronary heart disease: the heart and soul study. Arch Intern Med 2007;167:1798-803.

20. Vrijens B, De Geest S, Hughes DA, et al. A new taxonomy for describing and defining adherence to medications. $\mathrm{Br} J$ Clin Pharmacol 2012;73:691-705.

21. Nguyen TM, La Caze A, Cottrell N. What are validated self-report adherence scales really measuring? A systematic review. Br J Clin Pharmacol 2014;77:427-45.

22. Girerd X, Hanon O, Anagnostopoulos $\mathrm{K}$, et al. [Assessment of antihypertensive compliance using a self-administered questionnaire: development and use in a hypertension clinic] Presse Med 2001;30:1044-8.

23. Gonzalez JS, Schneider HE, Wexler DJ, et al. Validity of medication adherence self-reports in adults with type 2 diabetes. Diabetes Care 2013;36:831-7.

24. Svarstad BL, Chewning BA, Sleath BL, et al. The Brief Medication Questionnaire: a tool for screening patient adherence and barriers to adherence. Patient Educ Couns 1999;37:113-24.

25. Morisky DE, Green LW, Levine DM. Concurrent and predictive validity of a self-reported measure of medication adherence. Med Care 1986;24:67-74.

26. Garfield S, Eliasson L, Clifford S, et al. Developing the Diagnostic Adherence to Medication Scale (the DAMS) for use in clinical practice. BMC Health Serv Res 2012;12:350.

27. Mannheimer S, Thackeray L, Huppler Hullsiek K, et al. A randomized comparison of two instruments for measuring self-reported antiretroviral adherence. AIDS Care 2008;20:161-9.

28. Streiner D, Norman GR. Health measurement scales: a practical guide to their development and use. 4th edn. Oxford: Oxford University Press, 2008:431.

29. Guyatt GH, Bombardier C, Tugwell PX. Measuring disease-specific quality of life in clinical trials. CMAJ 1986;134:889-95.

30. Elwyn G, O'Connor A, Stacey D, et al. Developing a quality criteria framework for patient decision aids: online international Delphi consensus process. BMJ 2006;333:417

31. Hawley ST, Zikmund-Fisher B, Ubel P, et al. The impact of the format of graphical presentation on health-related knowledge and treatment choices. Patient Educ Couns 2008;73:448-55.

32. Zeller A, Schroeder K, Peters TJ. An adherence self-report questionnaire facilitated the differentiation between nonadherence and nonresponse to antihypertensive treatment. J Clin Epidemiol 2008;61:282-8.

33. Huber CA, Szucs TD, Rapold R, et al. Identifying patients with chronic conditions using pharmacy data in Switzerland: an updated mapping approach to the classification of medications. BMC Public Health 2013;13:1030.

34. Beaton DE, Bombardier C, Guillemin F, et al. Guidelines for the process of cross-cultural adaptation of self-report measures. Spine 2000:25:3186-91.

35. Epstein J, Santo RM, Guillemin F. A review of guidelines for cross-cultural adaptation of questionnaires could not bring out a consensus. J Clin Epidemiol 2015;68:435-41.

36. Terwee CB, Bot SD, de Boer MR, et al. Quality criteria were proposed for measurement properties of health status questionnaires. J Clin Epidemiol 2007;60:34-42. 
37. Tran VT, Montori VM, Eton DT, et al. Development and description of measurement properties of an instrument to assess treatment burden among patients with multiple chronic conditions. BMC Med 2012;10:68.

38. Vijan S, Hayward RA, Ronis DL, et al. Brief report: the burden of diabetes therapy: implications for the design of effective patient-centered treatment regimens. J Gen Intern Med 2005;20:479-82.

39. Shrout PE, Fleiss JL. Intraclass correlations: uses in assessing rater reliability. Psychol Bull 1979;86:420-8.

40. Juniper EF, Guyatt GH, Jaeschke R. How to develop and validate a new health-related quality of life instrument. In: Spilker B, ed. Quality of life and pharmacoeconomics in clinical trials, 2nd edition. Philadelphia: Lippincott-Raven Publishers; 1996:49-56.
41. Streiner DL, Kottner J. Recommendations for reporting the results of studies of instrument and scale development and testing. $J A d v$ Nurs 2014;70:1970-9.

42. Kesselheim AS, Misono AS, Shrank WH, et al. Variations in pill appearance of antiepileptic drugs and the risk of nonadherence. JAMA Intern Med 2013;173:202-8.

43. Kesselheim AS, Bykov $\mathrm{K}$, Avorn J, et al. Burden of changes in pill appearance for patients receiving generic cardiovascular medications after myocardial infarction: cohort and nested case-control studies. Ann Intern Med 2014;161:96-103.

44. McHorney CA, Gadkari AS. Individual patients hold different beliefs to prescription medications to which they persist vs nonpersist and persist vs nonfulfill. Patient Prefer Adherence 2010;4:187-95. 